\title{
Novel Synthesis of 2,3-Bisboryl-1,3-dienes from 1-Bromo-1-lithioethene and 1,1-Bisborylalkenes
}

\author{
Masaki Shimizu,* Takuya Kurahashi, Tamejiro Hiyama \\ Department of Material Chemistry, Graduate School of Engineering, Kyoto University, Yoshida, Sakyo-ku, Kyoto 606-8501, Japan \\ Fax +81 75753 5555; E-mail: shimizu@ npc05.kuic.kyoto-u.ac.jp \\ Received 2 February 2001 \\ This paper is dedicated to Professor Ryoji Noyori on the occasion of his retirement of Nagoya University, Japan
}

\begin{abstract}
Treatment of 1,1-[bis(pinacolato)boryl]alkenes with excess of 1-bromo-1-lithioethene was found to give 2,3-bis[(pinacolato)boryl]-1,3-dienes in moderate to good yields. Synthetic applications of 2,3-[bis(pinacolato)boryl]-1,3-butadiene were also demonstrated.
\end{abstract}

Key words: boron, lithium, carbenoids, insertion, alkenes

Alkenylboron compounds are readily accessible and extremely useful reagents in organic synthesis. ${ }^{1}$ In contrast, bis(alkenylboron) compounds have attracted less attention probably because their facile syntheses are quite limited, ${ }^{2}$ though bis(alkenylboron) compounds would be employed for an efficient synthesis of polysubstituted olefins through double carbon-carbon bond formation with retention of configuration by a simple experimental operation. Very recently, we found that treatment of bis(pinacolato)diboron $\mathbf{1}$ or (dimethylphenylsilyl)(pinacolato)boron 3 with 1-halo-1-alkenyllithium gave the corresponding 1,1-bisborylalkenes $\mathbf{2}$ or 1-silyl-1-borylalkenes $\mathbf{4}$, respectively. ${ }^{3}$ In particular, 2 is a parent example of bis(alkenylboron) compounds (eq.).

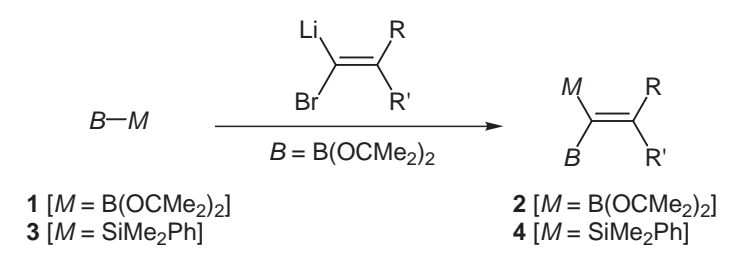

Equation

During the course of the synthetic studies, we eventually found that 2,3-bisboryl-1,3-dienes 5a were produced when excess of 1-bromo-1-lithioethene was treated with $\mathbf{1}$. Formation of $\mathbf{5} \mathbf{a}$ was ascribed to the reaction of 1,1-bisborylethene $\mathbf{2 a}$ with $\mathrm{CH}_{2}=\mathrm{CBrLi}$ followed by 1,2-migration of a carbon (Scheme 1). ${ }^{1}$ We report herein that the synthesis of 2,3-bisboryl-1,3-dienes is general, ${ }^{4}$ and bisborylated 1,3-dienes 5 serve as useful precursors of complex 1,3-dienes. ${ }^{5}$ In addition, introduction of two boryl groups into a 1,3-diene unit enhances the synthetic utility of the addition products.

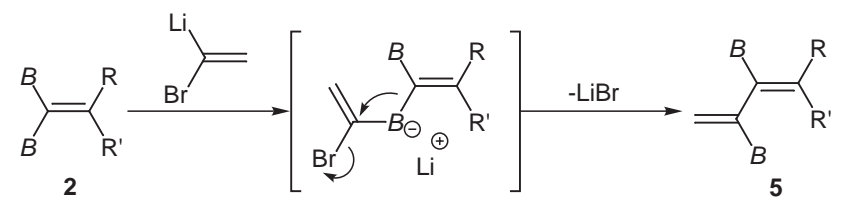

Scheme $1 \quad B=\mathrm{B}\left(\mathrm{OCMe}_{2}\right)_{2}$

Treatment of 1-bromo-1-lithioethene (1 mol), generated from vinyl bromide and lithium 2,2,6,6-tetramethylpiperidide (LiTMP) in THF-Et ${ }_{2} \mathrm{O}(2: 1)$ at $-110^{\circ} \mathrm{C}$, with 1,1 bis[(pinacolato)boryl]ethene $2 \mathbf{a}(1 \mathrm{~mol})$ at $-110{ }^{\circ} \mathrm{C}$ gave 2,3-bisboryl-1,3-butadiene 5a in 7\% yield (Scheme 2 ). In view that diboron 1 reacts with an equimolar amount of 1bromo-1-lithioethene to give $\mathbf{2 a}$ in $91 \%$ yield, ${ }^{3}$ the low yield indicates that the reaction of the carbenoid with $\mathbf{2 a}$ is slower than with $\mathbf{1}$ and apparently competes with the decomposition of the lithium carbenoid. Then, we increased the amount of the carbenoid reagent, and observed that $72 \%$ yield was achieved when 5 molar equivalents of vinyl bromide and LiTMP were employed as shown in Scheme $2{ }^{6,7}$ Noteworthy is that $\mathbf{5 a}$ can be purified by column chromatography on silica gel since 2-boryl-1,3-diene is reported to be highly susceptible to dimerization. ${ }^{8}$ Carbenoid generation carried out in the presence of $\mathbf{2 a}$ gave $\mathbf{5 a}$ in lower yield (59\%), while reaction of 2-substituted 1bromo-1-lithioethene with $\mathbf{2 a}$ did not proceed at all.

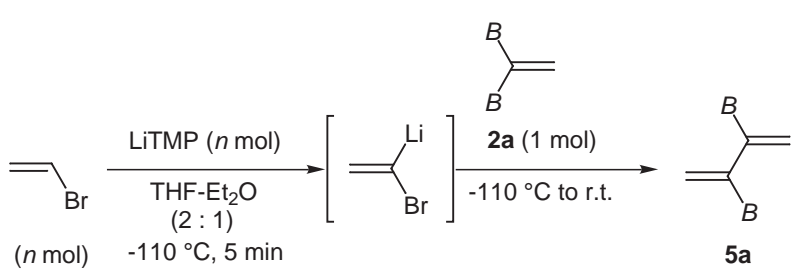

Yield (\%) of 5a: $7(n=1), 46(n=3), 72(n=5), 60(n=10)$

Scheme 2 Synthesis of 2,3-bisboryl-1,3-diene 5a

The optimized conditions were applied to 2-monosubstituted bisborylethenes $\mathbf{2 b}$ and $\mathbf{2 c}$. The corresponding conjugated triene $\mathbf{5 b}$ as a $E / Z$ mixture $(73: 27)$ and dienyne $\mathbf{5 c}$ as the only $E$-isomer were respectively isolated in $74 \%$ and $38 \%$ yields. ${ }^{9}$ The stereochemical outcome indicates that 1-bromo-1-lithioethene preferentially attacks the 
sterically less hindered boron atom of $\mathbf{2}$. Reaction of 2,2disubstituted-1,1-diborylethenes $2 \mathbf{d}$ and $2 \mathrm{e}$ also took place smoothly, giving rise to $\mathbf{5 d}$ and $\mathbf{5 e}$ in good yields.
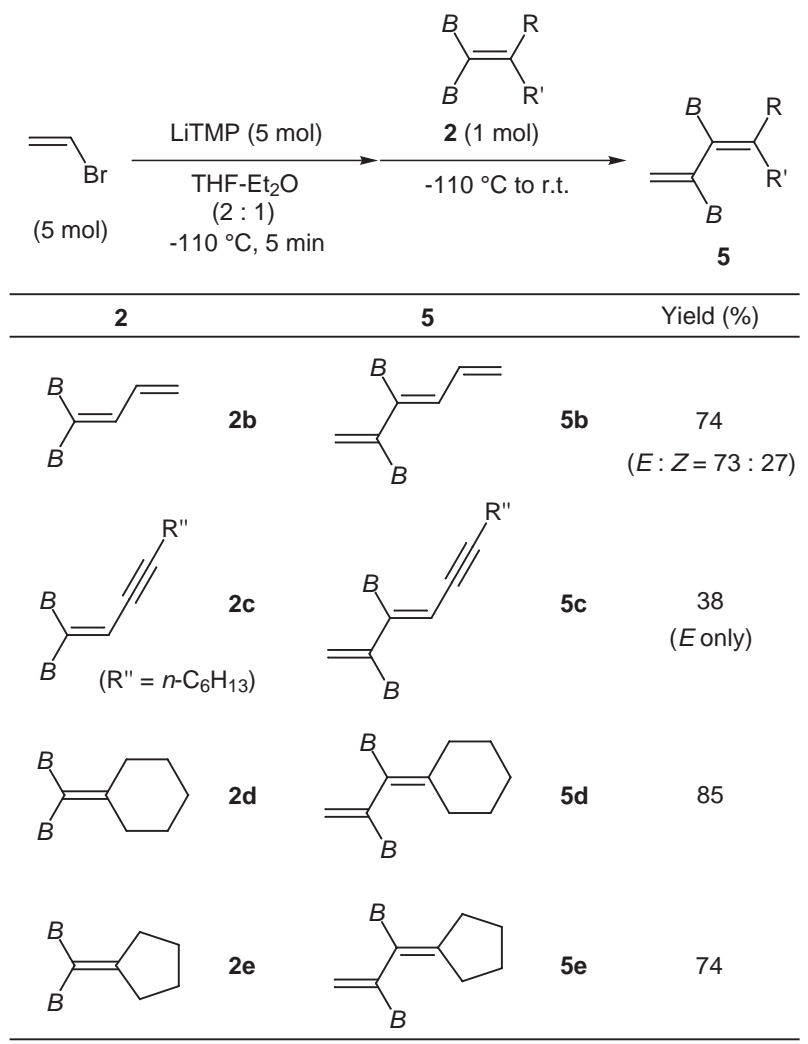

Scheme 3 Synthesis of 2,3-bisboryl-1,3-diene 5

One-pot synthesis of $\mathbf{5 a}$ from $\mathbf{1}$ is possible. As shown in Scheme 4, treatment of vinyl bromide (5 mol) with LiTMP $(5 \mathrm{~mol})$ followed by the addition of diboron 1 produced $\mathbf{5 a}$ in $82 \%$ yield.

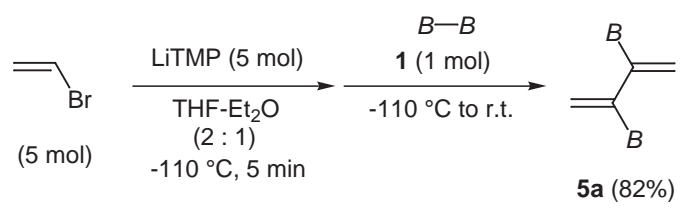

Scheme 4 One-pot synthesis of 5 a from 1

Synthetic utility of 2,3-bisboryl-1,3-butadiene 5a is demonstrated in Scheme 5. Diels-Alder reaction of 5a is particularly accelerated by the two boryl groups and indeed proceeded with maleimide even at room temperature to give 1,2-bisborylated cyclohexene $\mathbf{6}$ in $93 \%$ yield. ${ }^{8,10}$ Cross-coupling reaction with iodobenzene catalyzed by $\mathrm{Pd}\left(\mathrm{PPh}_{3}\right)_{4}$ allowed us to prepare 2,3-diphenyl-1,3-butadiene 7. ${ }^{11}$ 1,2,3,4-Tetraboryl-2-butene $\mathbf{8}$ or 1-silyl-2,3,4tris(boryl)-2-butene 9 was synthesized as a single diastereomer by Pt-catalyzed 1,4-addition reaction with bis(pinacolato)diboron $\mathbf{1}$ or (dimethylphenylsilyl)(pina- colato)boron $3{ }^{12}$ The highly borylated compounds $\mathbf{8}$ and 9 contain both alkenyl- and allylmetal moieties and thus may serve as valuable synthetic reagents.

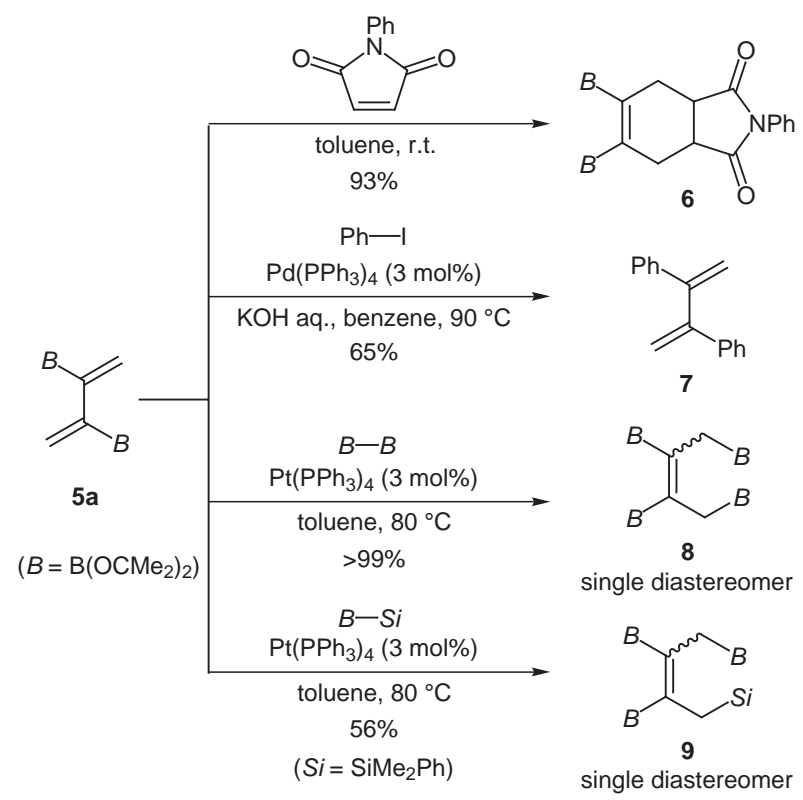

Scheme 5 Synthetic applications of 2,3-diboryl-1,3-butadiene

In summary, we have established a novel synthesis of 2,3bisboryl-1,3-dienes from 1-bromo-1-lithioethene and 1,1bisborylalkenes. We can transform 2,3-bisboryl-1,3dienes into various types of complex molecules using the boron functionality as a key element before/after unique reactions of 1,3-dienes. Further studies based on 2,3-bisboryl-1,3-dienes are in progress in our laboratory.

\section{Acknowledgement}

This work was supported by a Grand-in-Aid for COE Research on Element Science, No. 12CE2005 from Ministry of Education, Culture, Sports, Science, and Technology, Japan.

\section{References and Notes}

(1) a) Negishi, E. In Comprehensive Organometallic Chemistry; Wilkinson, G., Stone, F. G. A., Abel, E. W., Eds.; Pergamon Press: New York, 1983; Vol. 7, p 303-322; b) Negishi, E.; Idacavage, M. J. Org. React. 1985, 33, 1-246; c) Pelter, A.; Smith, K.; Brown, H. C. Borane Reagents; Academic Press: New York, 1988; d) Vaultier, M.; Carboni, B. In Comprehensive Organometallic Chemistry II; Abel, E. W., Stone, F. G. A., Wilkinson, G., Eds.; Pergamon Press: Oxford, 1995; Vol. 11, p 191-276; e) Matteson, D. S. In Stereodirected Synthesis with Organoboranes; Springer: Berlin, 1995, p 120161.

(2) vic-Bisborylalkenes: a) Ishiyama, T.; Matsuda, N.; Miyaura, N.; Suzuki, A. J. Am. Chem. Soc. 1993, 115, 11018-11019; b) Ishiyama, T.; Matsuda, N.; Murata, M.; Ozawa, F.; Suzuki, A.; Miyaura, N. Organometallics 1996, 15, 713-720; gemBisborylalkenes: c) Matteson, D. S.; Tripathy, P. B. J. Organomet. Chem. 1974, 69, 53-62; d) Matteson, D. S.; Furue, M. J. Organomet. Chem. 1974, 69, 63-67; e) Moody, 
R. J.; Matteson, D. S. J. Organomet. Chem. 1978, 152, 265270; Tetraborylethene: f) Maderna, A.; Pritzkow, H.; Siebert, W. Angew. Chem. Int. Ed. Engl. 1996, 35, 1501-1503; g) Bluhm, M.; Maderna, A.; Pritzkow, H.; Bethke, S.; Gleiter, R.; Siebert, W. Eur. J. Inorg. Chem. 1999, 1693-1700.

(3) Hata, T.; Kitagawa, H.; Masai, H.; Kurahashi, T.; Shimizu, M.; Hiyama, T. Angew. Chem., Int. Ed. 2001, 40, 790-792.

(4) Bisboryl-1,3-dienes: a) Zweifel, G.; Polston, N. L. J. Am. Chem. Soc. 1970, 92, 4068-4071; b) Maercker, A.; Brieden, W.; Schmidt, T.; Lutz, H. D. Angew. Chem., Int. Ed. Engl. 1989, 28, 477-478; c) Bubnov, Y. N. Pure Appl. Chem. 1991, 63, 361-364; d) Enders, M.; Kramer, A.; Pritzkow, H.; Siebert, W. Angew. Chem., Int. Ed. Engl. 1991, 30, 84-85; e) Metzler, N.; Noth, H.; Thomann, M. Organometallics 1993, 12, 2423 2425; f) Hauss, J.; Pritzkow, H.; Siebert, W. Chem. Ber. 1995, 128, 183-185; g) Desurmont, G.; Klein, R.; Uhlenbrock, S.; Laloe, E.; Deloux, L.; Giolando, D. M.; Kim, Y. W.; Pereira, S.; Srebnik, M. Organometallics 1996, 15, 3323-3328.

(5) a) Oppolzer, W. In Comprehensive Organic Synthesis; Trost, B. M., Fleming, I., Eds.; Pergamon Press: Oxford, 1991; Vol. 5, p 315-400; b) Roush, W. R. In Comprehensive Organic Synthesis; Trost, B. M., Fleming, I., Eds.; Pergamon Press: Oxford, 1991; Vol. 5, p 513-550.

(6) Further insertion of the carbenoid reagent appears to be inhibited; a reason is unclear at present.

(7) Representative procedure of 5a: Butyllithium in hexane (1.56 $\mathrm{M}, 321 \mu \mathrm{L}, 0.49 \mathrm{mmol}$ ) was added to a solution of 2,2,6,6tetramethylpiperidine $(84 \mu \mathrm{L}, 0.50 \mathrm{mmol})$ in a mixture of THF $(1 \mathrm{~mL})$ and diethyl ether $(0.5 \mathrm{~mL})$ at $0{ }^{\circ} \mathrm{C}$, and the resulting solution was stirred at $0{ }^{\circ} \mathrm{C}$ for $5 \mathrm{~min}$. To this solution was added a THF solution of vinyl bromide $(1.0 \mathrm{M}, 500 \mu \mathrm{L}, 0.50$ mmol) at $-110{ }^{\circ} \mathrm{C}$ and 1,1 -[bis(4,4,5,5-tetramethyl-1,3,2dioxaborolan-2-yl)] ethene (2a) $(25 \mathrm{mg}, 0.10 \mathrm{mmol})$ in THF $(0.1 \mathrm{~mL})$ successively. The resulting mixture was gradually allowed to warm up to room temperature and stirred for $12 \mathrm{~h}$. The reaction mixture was quenched with three drops of sat. aq $\mathrm{NH}_{4} \mathrm{Cl}$, and diluted with diethyl ether $(10 \mathrm{~mL})$ and water $(3$ $\mathrm{mL}$ ). The organic layer was separated, dried over anhydrous magnesium sulfate, and concentrated in vacuo to give a colorless solid, which was purified by column chromatography (200 mesh silica gel, ethyl acetatehexane $=1: 10)$ to give $5 \mathbf{a}(22 \mathrm{mg}, 72 \%$ yield $) . \mathrm{Mp}: 140{ }^{\circ} \mathrm{C}$ (dec). TLC: $\mathrm{R}_{\mathrm{f}} 0.33$ (hexane-ethyl acetate $=10: 1$ ). ${ }^{1} \mathrm{H}$ NMR $\left(200 \mathrm{MHz}, \mathrm{CDCl}_{3}\right) \delta 1.28(\mathrm{~s}, 24 \mathrm{H}), 5.85(\mathrm{~d}, J=3.9 \mathrm{~Hz}, 2 \mathrm{H})$, $5.96(\mathrm{~d}, J=3.9 \mathrm{~Hz}, 2 \mathrm{H}) ;{ }^{13} \mathrm{C} \mathrm{NMR}\left(50 \mathrm{MHz}, \mathrm{CDCl}_{3}\right) \delta 24.8$, 83.5, 130.6; IR (nujol) 1460, 1375, 1340, 1300, 1277, 1218, $1120,1102,959,880,847,740,682 \mathrm{~cm}^{-1} ; \mathrm{MS}(70 \mathrm{eV}) \mathrm{m} / \mathrm{z} 307$ $\left(\mathrm{M}^{+}+1,7.0\right), 306\left(\mathrm{M}^{+}, 40.0\right), 305\left(\mathrm{M}^{+}-1,19.6\right), 291\left(\mathrm{M}^{+}-\mathrm{Me}\right.$, 8.5), 165 (100). Anal. Calcd for $\mathrm{C}_{16} \mathrm{H}_{28} \mathrm{~B}_{2} \mathrm{O}_{4}: \mathrm{C}, 62.80 ; \mathrm{H}$, 9.22. Found: C, 62.53; H, 9.42.

(8) Kamabuchi, A.; Miyaura, N.; Suzuki, A. Tetrahedron Lett. 1993, 34, 4827-4828.

(9) Stereochemistry of $\mathbf{5 b}$ was assigned by ${ }^{1} \mathrm{H}$ NMR with 6(dimethylphenylsilyl)-5-(4,4,5,5-tetramethyl-1,3,2dioxaborolan-2-yl)-4-nonene as a reference compound. Suginome, M.; Ohmori, Y.; Ito, Y. J. Organomet. Chem. 2000, 611, 403-413.

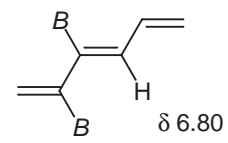

$(E)-5 \mathbf{b}$

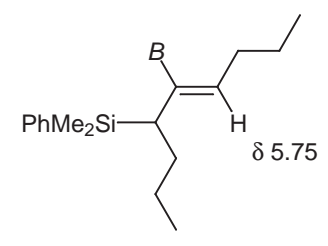

(E)-isomer

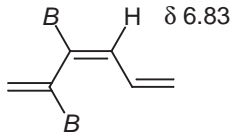

(Z)-5b

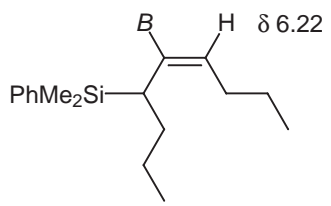

(Z)-isomer
(10) The detail of Diels-Alder reaction of $\mathbf{5} \mathbf{a}$ will be reported in due course.

(11) Miyaura, N.; Suzuki, A. Chem. Rev. 1995, 95, 2457-2483.

(12) Bisborylation of 1,3-dienes: Ishiyama, T.; Yamamoto, M.; Miyaura, N. Chem. Commun. 1996, 2073-2074; Ishiyama, T.; Yamamoto, M.; Miyaura, N. Chem. Commun. 1997, 689-690; Silylborylation of 1,3-dienes: Suginome, M.; Nakamura, H.; Matsuda, T.; Ito, Y. J. Am. Chem. Soc. 1998, 120, 4248-4249; Suginome, M.; Matsuda, T.; Yoshimoto, T.; Ito, Y. Org. Lett. 1999, $1,1567-1569$.

Article Identifier:

1437-2096,E;2001,0,SI,1006,1008,ftx,en;Y04101ST.pdf 